\title{
First Course in Global Studies
}

\section{Fatma Al Hammadi}

Zayed University, Dubai

Global Studies 1 (COL-150), was my favorite course last year. In this course we learned different things such as globalization, identity, and sociology. In the globalization part we learned about different forms of globalization: communication globalization, cultural globalization, environmental globalization, and economic globalization. We learned about these concepts and how they have affected the world where we live and have made it shrink. In the part that talks about identity we learned about the identity of people within a huge diversity, and how globalization has led to this diversity in society. In the part that talks about sociology we learned about sociology and how it plays a role in a society's life.

The instructor of my COL 150 course was Dr. James Piecowye. James is a smart professor: he really helped us to understand the material. For example, before we start a new lesson he asks us to form groups of 4 girls and gives us questions related to the new lesson. Then we have to answer them depending on our general knowledge. When we finish this practical work he starts to explain the lesson to us. Sometimes, to make it easier for us to understand the lesson by depending on ourselves, he asks us to form groups and asks us questions related to the lesson. Then we can use the book to find out the answers, and write them on the board. In addition to these methods, he gives us assignments that show our creativity and at the same time help us to understand the materials. For example, in COL 150 we had to design posters that include the subject of something related to COL 150 materials, and we had to write essays about globalization and culture, which helped us to be more critical.

The reason why I liked this course is that it talks about things that interest me such as cultures, globalization, sociology, and identity. I am a sociable person and I like to learn about the people who live around me and about the things that happen around me. I like to think critically about these things. I also like to learn about these things because it makes me aware of the global issues around us. We live in a globalized world so we have to be aware of what happens around us and why it happens.

As a person who likes to be critical, I found COL 150 a great chance to improve my critical thinking, because when you study COL 150 you have to be critical. When you read something from the book you have to use your own point of view in order to understand it. You have to think about the factors around you and how they have led to a certain case or situation.

Because of COL 150 I have become aware of many things such as the clash of civilizations, the effects of globalization, and the relevance of sociology. These concepts are important to learn because they help us understand what is happening around us in this huge world.

\section{Author}

Fatima Al Hammadi is a student in the College of Communication and Media Sciences at Zayed University, Dubai. 